\title{
Quantitative Magnetic Resonance Imaging of the Pancreas of Individuals With Diabetes
}

\author{
John Virostko ${ }^{1,2,3 *}$ \\ ${ }^{1}$ Department of Diagnostic Medicine, University of Texas at Austin, Austin, TX, United States, ${ }^{2}$ Livestrong Cancer Institutes, \\ University of Texas at Austin, Austin, TX. United States, ${ }^{3}$ Department of Oncology, University of Texas at Austin, Austin, TX, \\ United States
}

OPEN ACCESS

Edited by: Guy A. Rutter,

Imperial College London, United Kingdom

Reviewed by:

Amelia K. Linnemann,

Indiana University, United States Marcia Hiriart, National Autonomous University of Mexico, Mexico

*Correspondence: John Virostko jack.virostko@austin.utexas.edu

Specialty section:

This article was submitted to Diabetes: Molecular Mechanisms, a section of the journal

Frontiers in Endocrinology

Received: 06 August 2020

Accepted: 28 October 2020

Published: 04 December 2020

Citation:

Virostko J (2020) Quantitative Magnetic Resonance Imaging of the Pancreas of Individuals With Diabetes.

Front. Endocrinol. 11:592349. doi: 10.3389/fendo.2020.592349
Magnetic resonance imaging (MRI) has the potential to improve our understanding of diabetes and improve both diagnosis and monitoring of the disease. Although the spatial resolution of MRI is insufficient to directly image the endocrine pancreas in people, the increasing awareness that the exocrine pancreas is also involved in diabetes pathogenesis has spurred new MRI applications. These techniques build upon studies of exocrine pancreatic diseases, for which MRI has already developed into a routine clinical tool for diagnosis and monitoring of pancreatic cancer and pancreatitis. By adjusting the imaging contrast and carefully controlling image acquisition and processing, MRI can quantify a variety of tissue pathologies. This review introduces a number of quantitative MRI techniques that have been applied to study the diabetic pancreas, summarizes progress in validating and standardizing each technique, and discusses the need for image analyses that account for spatial heterogeneity in the pancreas.

Keywords: MRI, volume, relaxometry, perfusion, type 2 diabetes, type 1 diabetes, diffusion, radiomic

\section{INTRODUCTION}

Recent advances in magnetic resonance imaging (MRI) technology have improved pancreas imaging, surmounting some of the difficulties inherent to the small, irregular shape of the pancreas, and its challenging location and susceptibility to motion. MRI of the pancreas has emerged into a valuable clinical tool for characterizing a number of pancreatic diseases. The staging and diagnosis of both acute (1) and chronic (2) pancreatitis often includes MRI. Furthermore, MRI can detect focal pancreatic lesions, and is employed clinically in both diagnosis of pancreatic cancer (3) and monitoring of therapeutic response (4). However, to date, MRI of the pancreas has had relatively limited impact on the study or management of diabetes. This likely stems in part from the established paradigm that diabetes effects only the endocrine pancreas, or islets, which are too small to be imaged by MRI. However, the involvement of exocrine pancreas in T1D and T2D is of renewed interest, as reviewed by Alexendra-Heymann et al. (5). As glucose, hormones, and other measures of glycemic control can be assessed using blood or urine tests, there may be an assumption that imaging is unnecessary. Indeed, two fields in which imaging has entered standard clinical practice, neurology and oncology, are both characterized by difficulty in directly assaying the tissue of interest and/or the absence of blood biomarkers. But while blood tests will likely always be the cornerstone of diabetes management, they are subject to important limitations. For instance, testing 
of A1C is hampered by standardization issues, poor sensitivity, and a lack of correlation with some pathophysiological hallmarks of diabetes (6). In type 1 diabetes (T1D), fasting hyperglycemia presents only after destruction of a majority of beta cells (7), suggesting that blood tests are a lagging indicator of beta cell loss due to a high insulin reserve. Circulating autoantibodies signify risk for T1D, but their presence can be transient and time to progression after autoantibody presentation is highly variable (8). These limitations and other aspects of diabetes care currently not well characterized by blood tests may be addressed in part by medical imaging.

This review focuses on quantitative MRI techniques and their application to study the pancreas in both type 1 and type 2 diabetes (T2D). These techniques are summarized in Table $\mathbf{1}$. Quantitative MRI refers to the objective measurement of parameters derived from digital images that characterize tissue attributes (9). This contrasts with the traditional qualitative assessment typically performed in standard radiology practice. Importantly, quantitative MRI techniques can map the entire pancreas, and thus identify regions of the pancreas with altered properties. This ability to interrogate spatial variation is significant, as histological studies have shown that the insult characteristic of both T1D $(10)$ and T2D $(11,12)$ can differ across the pancreas. Furthermore, quantitative MRI parameters can be standardized across multiple sites for incorporation into clinical trials, and ultimately used to guide clinical practice. However, in order for quantitative MRI to be adopted to study the diabetic pancreas, the biological underpinnings of imaging results must be validated against gold standard measurements and techniques must be repeatable and reproducible across imaging centers. This review highlights a range of quantitative MRI parameters that may improve our understanding of the diabetic pancreas, benchmarks each technique's progress in validation and standardization, and concludes with a discussion of image analyses that can accurately characterize pancreas heterogeneity.

\section{PANCREAS VOLUME}

Owing to its exquisite soft tissue contrast, MRI can delineate pancreas borders from neighboring organs, which can in turn be used to quantify pancreas size. The pancreas has long been known to be smaller in type 1 diabetes (13) and more recently in type 2 diabetes as well (14). A meta-analysis validated these findings across multiple studies and found smaller pancreas size in T1D than T2D (15). Of note, the degree of pancreas reduction in both type T1D and T2D far exceeds the volume of the endocrine pancreas, suggesting exocrine involvement in diabetes pathogenesis. These imaging findings are supported by histological studies of the pancreas from T1D donors which found reduced numbers of acinar cells (16) and altered exocrine cell expression (17) versus controls. Investigations into the temporal dynamics of pancreas size in T1D have found reduced pancreas size at diagnosis $(18,19)$, in individuals at risk for disease $(20,21)$, and longitudinal declines over the course of disease (20). Example images demonstrating the longitudinal decline seen in pancreas size in one individual with T1D is shown in Figure 1. Taken together, these studies suggest that alterations in pancreas size may be an early hallmark of T1D risk and may correlate with disease progression.

The relationship between pancreas volume and beta cell mass or function remains unclear. An islet transplantation study found a direct correlation between pancreas size and islet yield, and that this relationship was dependent on donor HbAlc (22). This suggests that pancreas size may reflect a combination of islet mass and function. Pancreas volume measurements performed using MRI display high accuracy, repeatability, and reproducibility. Porcine pancreas volume calculated from MRI demonstrated excellent correlation with gold standard water displacement measurements (23), indicating the accuracy of the technique. Furthermore, in human subjects who received MRI scans in quick succession, measurements of pancreas

TABLE 1 | Quantitative magnetic resonance imaging (MRI) techniques.

\begin{tabular}{|c|c|c|c|c|c|}
\hline MRI Technique & $\begin{array}{l}\text { Pancreas Pathology } \\
\text { Interrogated }\end{array}$ & $\begin{array}{l}\text { Change } \\
\text { in T1D }\end{array}$ & $\begin{array}{l}\text { Change } \\
\text { in T2D }\end{array}$ & $\begin{array}{l}\text { Biological } \\
\text { Confounders }\end{array}$ & Technical Confounders \\
\hline Anatomical MRI & Pancreas Volume & $\downarrow \downarrow$ & $\downarrow$ & Age; weight & \\
\hline Fat Fraction Mapping & Fat infiltration & $\leftrightarrow$ & $\uparrow$ & $\begin{array}{l}\text { Age, sex, visceral } \\
\text { adiposity }\end{array}$ & MRI acquisition; pancreas heterogeneity \\
\hline $\begin{array}{l}\text { Longitudinal Relaxation } \\
\text { (T1) }\end{array}$ & Fibrosis & $?$ & $?$ & Age & $\begin{array}{l}\text { MRI acquisition; magnetic field strength; pancreas } \\
\text { heterogeneity }\end{array}$ \\
\hline $\begin{array}{l}\text { Extracellular Volume } \\
\text { Fraction (ECV) }\end{array}$ & Fibrosis & $?$ & $\uparrow$ & & $\begin{array}{l}\text { MRI acquisition; contrast agent administration; magnetic field } \\
\text { strength; pancreas heterogeneity }\end{array}$ \\
\hline $\begin{array}{l}\text { Diffusion-Weighted } \\
\text { Imaging (DWI) }\end{array}$ & $\begin{array}{l}\text { Cell density; membrane } \\
\text { integrity; fibrosis }\end{array}$ & $\uparrow$ & $?$ & Age, sex & $\begin{array}{l}\text { MRI acquisition; magnetic field strength; pancreas } \\
\text { heterogeneity }\end{array}$ \\
\hline $\begin{array}{l}\text { Dynamic Contrast- } \\
\text { Enhanced (DCE) }\end{array}$ & $\begin{array}{l}\text { Perfusion; vascular } \\
\text { permeability }\end{array}$ & $?$ & $\uparrow$ & & $\begin{array}{l}\text { MRI acquisition; contrast agent administration; processing } \\
\text { technique; pancreas heterogeneity }\end{array}$ \\
\hline Arterial Spin Labeling (ASL) & Perfusion & $?$ & $?$ & & MRI acquisition; pancreas heterogeneity \\
\hline $\begin{array}{l}\text { Incoherent Intravoxel } \\
\text { Motion (IVIM) }\end{array}$ & Microvascular perfusion & $?$ & $?$ & & MRI acquisition; processing technique \\
\hline $\begin{array}{l}\text { Blood Oxygen Level } \\
\text { Dependent (BOLD) }\end{array}$ & $\begin{array}{l}\text { Perfusion; oxygen } \\
\text { consumption }\end{array}$ & $?$ & $?$ & & \\
\hline $\begin{array}{l}\text { Magnetic Resonance } \\
\text { Elastography (MRE) }\end{array}$ & Stiffness; fibrosis & $?$ & $\uparrow$ & Age & MRI acquisition; processing technique \\
\hline
\end{tabular}

$\uparrow=$ increase; $\downarrow==$ decrease; $\leftrightarrow$ = no change; ? = unknown. 

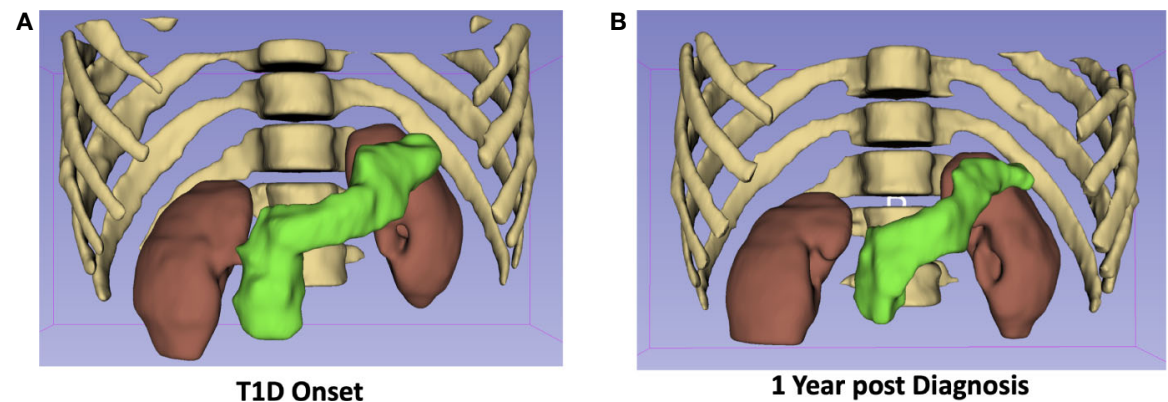

FIGURE 1 | The pancreas of a 19-year-old male at diagnosis with T1D (A) is 25\% smaller one-year post diagnosis (B). The pancreas is displayed in green with the kidneys, ribs, and spine shown for anatomical context.

volume were highly repeatable $(24,25)$. Pancreas borders can be difficult to delineate, which may lead to reader subjectivity in pancreas volume measurements. However, reproducibility across multiple readers reveals good agreement between two readers outlining the same image $(24,25)$. One caveat is that pancreas volume changes over the course of the human lifespan in the absence of disease, with rapid increases in size over childhood and pancreas atrophy in later life (14). Current quantification of pancreas size typically normalizes to body weight or surface area to account for these dynamics in pancreas size over the lifespan. Other factors that account for the large variations in pancreas volume seen between individuals are currently not known, but warrant further investigation.

\section{FAT FRACTION MAPPING}

MRI can measure the fat composition of tissue, as protons associated with fat and water spin with slightly different frequencies. Thus, their relative concentrations in a voxel (a portmanteau of "volume element", i.e., a three-dimensional pixel) of interest are relatively easy to separate. The relationship between pancreatic fat deposition and diabetes has been demonstrated in rodent models, in which ectopic fat accumulation leads to beta cell dysfunction (26). Similarly, MRI studies of people with T2D have demonstrated higher pancreatic fat associated with reduced beta cell function $(27,28)$. However, a number of other studies have failed to find a correlation between T2D and pancreatic fat content $(29,30)$. MRI may be sensitive to declines in pancreatic fat content. A study of diet-induced reversal of T2D found that diabetes reversal was accompanied by a decline in pancreatic fat fraction (31). Furthermore, pancreatic fat content may be increased in individuals at risk for developing T2D $(32,33)$ (Figure 2). In contrast with studies of T2D, MRI measures of pancreatic fat content are not altered in T1D (34), although some autopsy studies have found fatty infiltrate in the pancreas of T1D donors.

In terms of standardization and validation, fat fraction measurements are relatively advanced, owing in part to the simplicity of the technique and the availability of standard processing tools from MRI vendors. Histological measures of fat content from resected pancreata and MRI quantification of fat fraction demonstrate excellent agreement (35). Furthermore, test-retest measurements of pancreatic fat content calculated using MR spectroscopy were found to be repeatable (36). However, a meta-analysis of five studies of pancreatic fat content in T2D demonstrated high heterogeneity in fat measurements between studies (15). As is typical of MRI techniques, the acquisition and processing used to calculate the
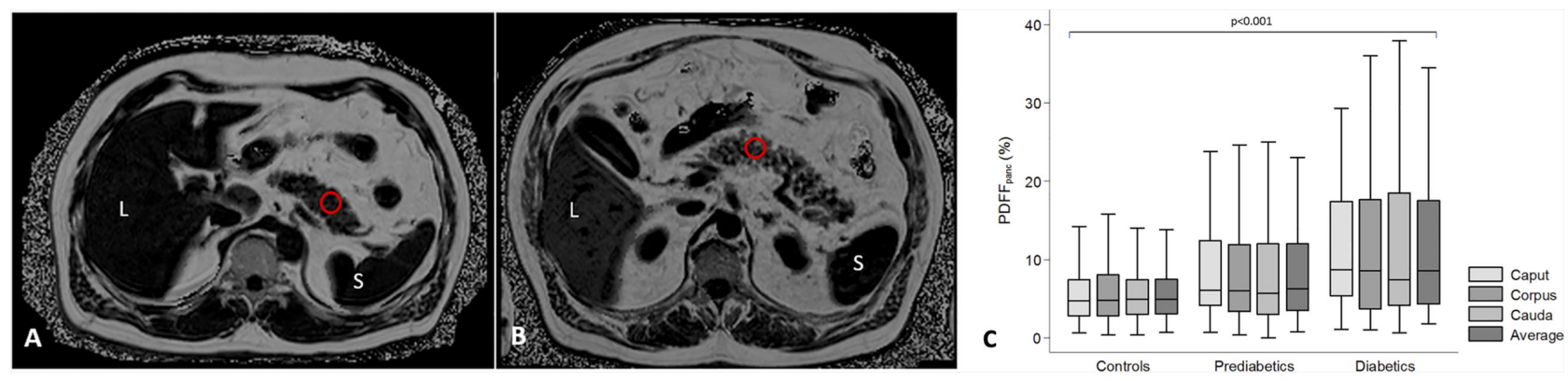

FIGURE 2 | Assessment of pancreatic fat content in subjects with lower (A) and higher (B) pancreatic fat content. Pancreatic fat content was measured as protondensity fat fraction $\left(\right.$ PDFF $_{\text {panc }}$ ) in a region of interest (red circle). $\mathrm{L}=$ liver; $\mathrm{S}=$ spleen. (C) Differences of pancreatic fat content between controls, subjects with prediabetes and diabetes displayed by box-and-whisker. Figure adapted from Heber et al. (32) under a Creative Commons License. 
fat fraction may impact the measurement (37), and may account for some of the differences seen between studies. Additionally, there exist regional variations in fat fraction throughout the pancreas, with different values in the head, body, and tail (38) (Figure 2). Finally, pancreatic fat content can be influenced by age, sex, and visceral adipose tissue (32). These demographic factors must be carefully accounted for when examining pancreatic fat content in individuals with diabetes. Unfortunately, reference standards for pancreatic fat content and its relationship with demographic factors are not well established at present.

\section{RELAXOMETRY}

\section{Longitudinal Relaxation (T1)}

Generation of an MR image relies on perturbation (or tipping) of protons from the main magnetic field by a radiofrequency pulse. Longitudinal relaxation refers to the return of these perturbed protons to their equilibrium state. The relaxation rate for each voxel within an image is a function of the intrinsic tissue parameters and is quantified by the time constant T1 (not to be confused with T1D). This is the basis for so called T1-weighted images, in which fat, injected contrast agents, and tissues with high protein content appear bright. Of note, the pancreas appears bright on a T1-weighted image, presumably due to the presence of high levels of aqueous protein in the acinar cells (39). In addition to qualitative T1-weighted images, one can employ a variety of techniques to quantify the $\mathrm{T} 1$ value characteristic of each voxel (40). Quantitative T1 mapping of the pancreas has demonstrated increased $\mathrm{T} 1$ in chronic pancreatitis (41), suggested that $\mathrm{T} 1$ may be sensitive to pancreatic inflammation. In studies of individuals with $\mathrm{T} 2 \mathrm{D}$, the $\mathrm{T} 1$ value was found to be higher than controls and correlated with HbA1c in one study (42). In contrast, another study found lower T1 values in T2D, although these values were also significantly different than controls (43).
The T1 of the pancreas in individuals with prediabetes is also increased (44) (Figure 3), suggesting that the alterations responsible for prolonged longitudinal relaxation may occur early in the development of T2D.

Validation and standardization of T1 measurements of the pancreas are underway. The foremost hurdle is determining the specific pancreas pathology reflected by $\mathrm{T} 1$ measurements. In the heart, histological measurements of fibrosis have correlated with T1 (45). Similar studies of resected pancreas are limited but have shown correlation of $\mathrm{T} 1$ with grade of pancreatic fibrosis (46). Standardization of T1 measurements must take into account known correlations between pancreas T1 values and age (47), although these associations have not been seen in all studies (48). Additionally, there is a known dependence of $\mathrm{T} 1$ on magnetic field strength of the MRI scanner (47). Finally, there are a variety of different techniques used to generate T1 maps. These methods display some discrepancies when applied to image the pancreas of the same individual (49). Further work is needed to standardize T1 mapping techniques for application to the pancreas.

\section{Extracellular Volume Fraction (ECV)}

Contrast agents are often used to alter tissue enhancement on MR images. These contrast agents are typically paramagnetic agents which shorten T1, thus leading to enhancement of tissues with high contrast agent perfusion. This technique is commonly used in oncological imaging, where well vascularized tumors "light up" after contrast agent administration. By examining changes in T1 maps in both the tissue of interest and blood and coupling it with the hematocrit, the extracellular volume fraction (ECV) can be calculated. ECV has been developed primarily for cardiac MRI applications, and has been found to be sensitive to a number of cardiomyopathies (50). In the pancreas, ECV has been shown to increase with increasing grade of chronic pancreatitis (51). ECV of the pancreas is also higher in individuals with T2D and, similar to native T1 maps, correlates with HbA1c (42).
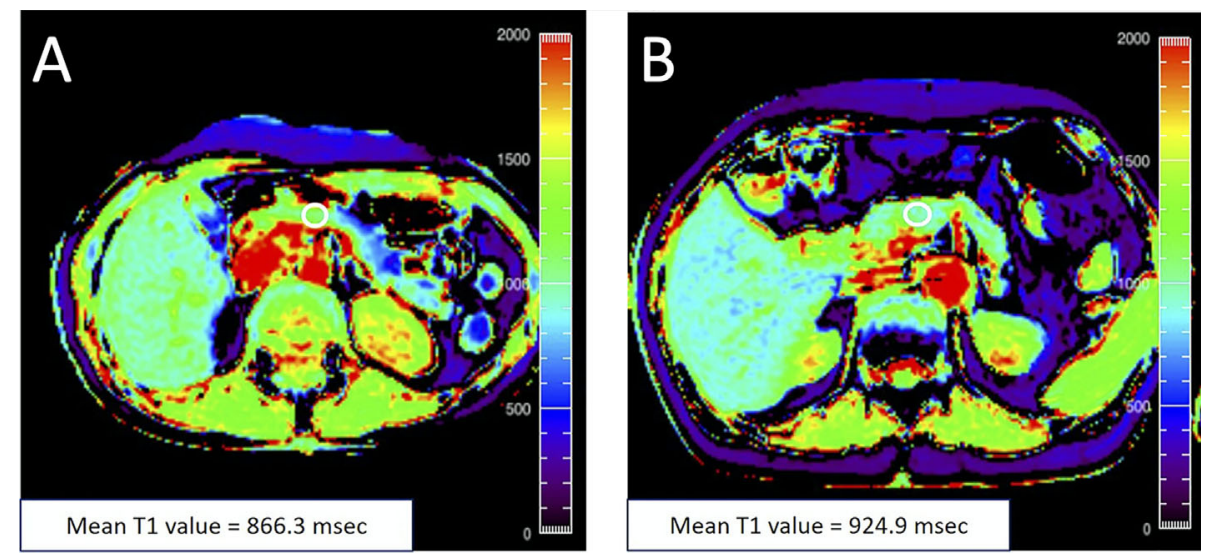

FIGURE 3 | (A) A 48-year-old female with an HbA1c value of 5.5\% with T1 map displayed in rainbow color shows the mean pancreatic T1 value of 866.3 msec. (B) A 76 -year-old female with an $\mathrm{HbA} 1 \mathrm{c}$ value of $6.0 \%$ with $\mathrm{T} 1$ map displayed in rainbow color shows the mean pancreatic T1 value of 924.9 msec. The white circle in each panel indicates a regions-of-interest (ROI) manually placed in the pancreas. Figure adapted from reference (44) with permission, () 2020 John Wiley \& Sons, Inc. 
The biological basis for increased ECV in the pancreas in diabetes is assumed to be due fibrosis. However, while MRI has demonstrated correlation between fibrosis and ECV in the heart (52), similar correlation of imaging and pathology are lacking in the pancreas. ECV values in the pancreas do not appear to be influenced by age or sex (47). The repeatability and reproducibility of ECV measurements have been established in the myocardium. These studies have demonstrated general agreement, although as with non-contrast enhanced T1 measurements, the technique used for quantification can impact the result (53). Of note, ECV requires administration of a contrast agent containing gadolinium, which has been the subject of recent concerns over long term brain retention.

\section{DIFFUSION-WEIGHTED IMAGING (DWI)}

Diffusion-weighted imaging (DWI) measures the random Brownian motion of water molecules within a voxel. In biological tissue, DWI reflects an amalgamation of cell density, cell membrane integrity, and viscosity. DWI can be quantified by adjusting the diffusion weighting (commonly referred to as the bvalue) of two images and comparing their intensities to yield the apparent diffusion coefficient (ADC). While early applications of DWI were primarily limited to the brain due to long imaging times, advances in MRI hardware and processing have reduced acquisition times for abdominal imaging. In the pancreas, MRI has proven useful for detecting and characterizing malignant pancreatic masses (54), similar to the success of DWI in other oncological applications. Furthermore, in chronic pancreatitis the ADC value has been found to be reduced compared with controls (55). Applications of DWI to study the diabetic pancreas are limited. One study found reduced ADC in individuals with fulminant T1D (55). Our study of individuals with recent onset T1D did not find differences in ADC versus controls when measurements were averaged throughout the pancreas (20). However, we did find altered distributions of ADC in the pancreas in T1D, with an increased number of voxels with high
ADC values in T1D. These areas of high ADC (corresponding to areas of increased water diffusion, and presumably inflamed tissue) were found in focal areas in the pancreas in T1D at a greater rate than control pancreas (Figure 4). In individuals with suspected pancreatic disease, a negative correlation was found between pancreatic ADC and HbAlc (56). In addition to ADC, DWI can be quantified using other metrics. For instance, diffusion kurtosis can be calculated by assuming non-Gaussian Brownian motion and acquiring DWI with strongly diffusion-weighted images (higher 'b-values'). This kurtosis is thought to reflect the restriction of water diffusion by cell membranes and other tissue microstructure. Similar to ADC, diffusion kurtosis was found to correlate with $\mathrm{HbAlc}$, with higher kurtosis in the group with highest HbAlc (56).

As DWI is a mixed measure that reflects a number of tissue parameters influencing water diffusion, the biological basis in the pancreas is still under investigation. One study of resected pancreas found reduced ADC in more fibrotic tissue (46), presumably reflecting increased cellular density in fibrous tissue. The ADC in healthy pancreas appears to display regional variation over the pancreas, with highest values in the pancreas head and lowest values in the body (57). ADC values are also influenced by age and sex (58). A study across multiple MRI scanners found that ADC measures of the pancreas are generally reproducible, although, similar to T1 measurements, ADC is influenced by magnetic field strength (59). Measurement of ADC in the pancreas is likewise influenced by the acquisition scheme. DWI acquired with higher diffusion weighting (higher b-values) results in a higher calculated ADC (60). Thus, accurately quantifying DWI of the diabetic pancreas requires standardization of image acquisition and normalization for pancreas anatomy and patient demographics.

\section{PERFUSION}

The endocrine pancreas is characterized by a dense network of capillaries, which receive a significantly higher rate of blood flow
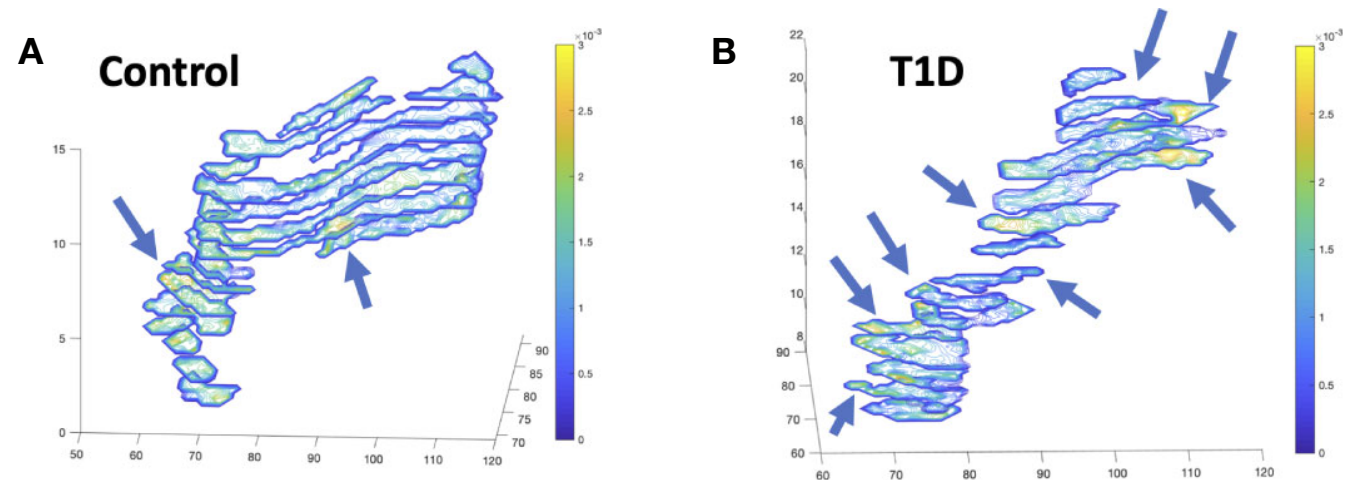

FIGURE 4 | Diffusion-weighted imaging (DWI) of the pancreas of a control (A) and individual with recent-onset T1D (B) displays focal alterations in the apparent diffusion coefficient (ADC), designated with arrows, with more focal areas of increased diffusion in T1D. Images display contiguous slices spanning the pancreas pseudo colored with contour plots according to the ADC value according to the ADC value in units of $\mathrm{mm}^{2} / \mathrm{s}$. 
than exocrine tissue (61). Alterations in islet vasculature have been found in the pancreas of organ donors with both T1D (62) and T2D (63). Thus, there is intense interest in studying islet blood flow and measuring it non-invasively in humans. MRI is widely used clinically to measure cerebral and myocardial perfusion. Four different MRI techniques for measuring perfusion are introduced below along with implications for pancreas imaging.

\section{Dynamic Contrast-Enhanced MRI (DCE-MRI)}

Dynamic contrast-enhanced MRI (DCE-MRI) relies upon acquisition of T1-weighted MR images after injection of a paramagnetic contrast agent. For further information on T1weighting and MR contrast agents, please refer back to Longitudinal Relaxation (T1) and Extracellular Volume Fraction (ECV), respectively. These contrast agents traverse through the vascular network and extravasate out of permeable vessels. The "dynamic" nature of this technique is derived from the acquisition of serial images over the time course of contrast agent distribution. The resultant time activity curves for each voxel in the image can be analyzed using pharmacokinetic models to yield estimates of perfusion parameters (64). DCEMRI has shown promise for imaging pancreatitis (65) and tracking response of pancreatic cancer to therapy (66). A study of DCE-MRI in individuals with T2D found increased vascular permeability but lower plasma volume in the pancreas (Figure 5), and that the magnitude of these perfusion changes increased with longer disease duration (67). A later study was unable to replicate these findings, and also did not determine an effect of glucose bolus on DCE-MRI parameters (43).

Correlation of DCE-MRI parameters and pathology has been performed in pancreas sections resected from individuals with pancreatic cancer. This analysis found correlation between DCE parameters and both fibrosis and microvascular density (68). Repeatability and reproducibility of DCE-MRI has been notoriously difficult to both measure and improve, as measurements can be influenced by acquisition parameters, choice of pharmacokinetic model, and contrast agent administration protocol. One study of repeatability in the pancreas found variability of $21 \%$ and also measured regional variations in the pancreas head, body, and tail (69). As with ECV measurements, contrast agent safety can be a concern when imaging in young individuals or performing repeat scans.

\section{Arterial Spin Labeling (ASL)}

Concerns over contrast agent injection have spurred the development of MRI techniques sensitive to perfusion that do not require exogenous sources of contrast. One such technique is known as arterial spin labeling (ASL) which magnetically labels blood flowing through a plane containing feeding blood vessels and images the resultant distribution of this tagged blood volume. ASL has demonstrated the ability to image increases in pancreas perfusion due to secretin (70), a hormone known to induce pancreatic fluid and bicarbonate secretion. Similarly, ASL of the pancreas has measured increased pancreas perfusion in response to glucose bolus (71). A study performing ASL during hyperglycemic clamp did not detect a difference between individuals with T1D and controls (72). However, ASL has been subject to a number of recent technological advances and continues to rapidly improve.

There have not been studies comparing ASL measurements in the pancreas to pathology. However, comparisons between DCEMRI derived perfusion with those from ASL display strong agreement (73). Thus, ASL may also reflect microvascular density throughout the pancreas. Of note, this parameter may vary across the pancreas, as ASL measurements found differences in the pancreas heady, body, and tail (74). The repeatability of ASL in the pancreas is moderate (70). Further work is needed to define the reproducibility of ASL across different MRI scanners and establish standardized acquisition and processing schemes.

\section{Intravoxel Incoherent Motion (IVIM)}

In previous discussion of diffusion-weighted MRI (Section 5), we noted that Brownian motion can be analyzed as having nonGaussian distribution. While analyzing high b-value data yields diffusion kurtosis measurements, fitting non-Gaussian diffusion using low b-value data yields intravoxel incoherent motion (IVIM). IVIM is thought to be sensitive to the microscopic perfusion of capillaries (75). In pancreas imaging, IVIM may help characterize benign versus malignant pancreas lesions (76). While we are not aware of studies of IVIM in individuals with diabetes, IVIM has demonstrated correlation with glucose stimulated perfusion increases in porcine models (77). Future
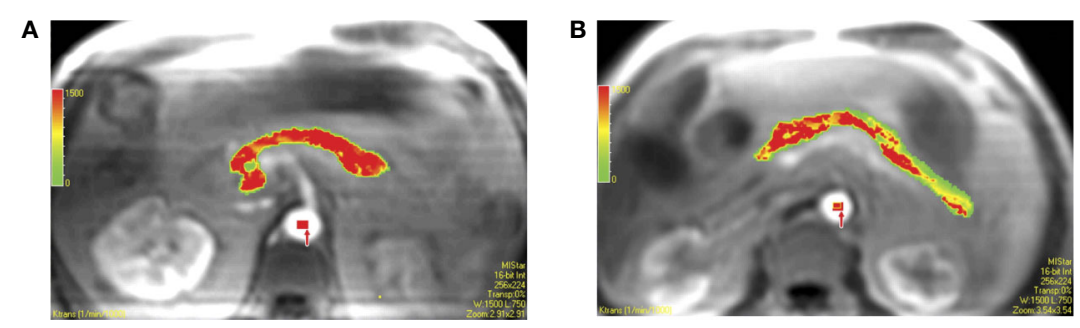

FIGURE 5 | Pixel-by-pixel color maps for transfer constant obtained with region of interest analysis. Calculated values of each pixel in region of interest can be seen in colors (red, yellow, and green are high, middle, and low values, respectively). (A) Color map in 61-year-old male coronary artery disease patient with type 2 diabetes shows a mean transfer constant $=1.291 \mathrm{~min}^{-1}$. (B) Color map in 54-year-old male coronary artery disease patient without type 2 diabetes shows a mean transfer constant $=0.787 \mathrm{~min}^{-1}$. Figure reproduced from reference (67) with permission, (C) 2009 RSNA. 
studies examining response to glucose in diabetes using IVIM are warranted.

The biological basis of IVIM in the pancreas has been demonstrated to derive from the blood component using blood suppression techniques (78). Furthermore, IVIM parameters agree with PET and microsphere measurements of pancreas perfusion (77). Repeatability and reproducibility of pancreas IVIM is influenced by both image acquisition and processing techniques (79). Currently, acquisition and processing of IVIM are complex techniques which are not well standardized across studies.

\section{Blood Oxygen Level Dependent (BOLD)}

BOLD imaging is widely used in neuroscience to image brain activity. BOLD reflects the accumulation of deoxyhemoglobin in response to oxygen consumption (which in the brain is posited to be a surrogate for neural activation). Fewer BOLD applications have been performed outside the central nervous system, although there are studies exploring renal oxygenation using BOLD (80). Similarly to IVIM, studies in individuals with diabetes are lacking, but there is a report showing alterations in BOLD MRI in the pancreas after glucose ingestion (81).

Decades after its first use, the biological basis of BOLD MRI is still under investigation. The biological correlate of BOLD signal in the pancreas, as well as its repeatability and reproducibility are not well characterized.

\section{MAGNETIC RESONANCE ELASTOGRAPHY (MRE)}

Magnetic resonance elastography (MRE) consists of imaging performed while a tissue is subjected to high frequency vibrations. MRE interrogates the movement of vibrationinduced shear waves through the body; these waves move slower in stiffer tissues. The primary clinical application of MRE currently is detecting fibrosis and cirrhosis in chronic liver disease. Applications to the pancreas are limited by the small size of the pancreas, but have found increased stiffness in chronic pancreatitis (82). Similar to perfusion measurements, MRE has been performed after glucose bolus which led to pancreas stiffening (83). Additionally, individuals with diabetes have been found to have higher pancreas stiffness than controls (84), as shown in Figure 6.

Histological studies of resected pancreata found a correlation between MRE-derived stiffness and both fibrosis and acinar atrophy (85). MRE measurements of pancreas stiffness are repeatable in test-retest studies, but are dependent on the vibration frequency used (83) and the age of the individual (86).

\section{RADIOMICS: ACCOUNTING FOR HETEROGENEITY THROUGHOUT THE PANCREAS}

MRI of the pancreas interrogates the complex structure of the pancreas encompassing islets, acinar cells, and the ductal network. There are known differences across the pancreas in the relative concentration of these components, with higher relative numbers of islet in the pancreas tail (87). A common theme throughout the MRI techniques introduced in this review is that they were frequently different in the pancreas head, body, and tail of the same individual. This was seen for measurements of fat fraction (38), diffusion (57), and perfusion measured by DCE (69) or ASL (74). Furthermore, spatial heterogeneity of the pancreas is further altered in diabetes, as has long been appreciated in autopsy studies of the pancreas from donors with diabetes (88). In T1D, there is marked spatial heterogeneity in the presence of the immune infiltrate characteristic of T1D (10) as well as individuals at risk for disease (89). Similarly, the islet amyloids and corresponding exocrine fibrosis found in T2D show lobular distribution throughout the pancreas $(11,12)$. The heterogeneity of quantitative MRI parameters throughout the pancreas is evident in Figures 2-6.

The spatial heterogeneity in MRI measures of the pancreas in general, and in the diabetic pancreas specifically, has important implications when quantifying MRI parameters. MRI analysis is commonly performed using a regions-of-interest (ROI) placed over a section of the pancreas, as demonstrated in Figures $\mathbf{2}$ and 3. However, in a mosaic tissue such as the pancreas the choice of ROI placement can influence the parameter of interest. An ROI placed in the same individual's pancreas may have significantly different values if it is placed in the pancreas head versus tail.
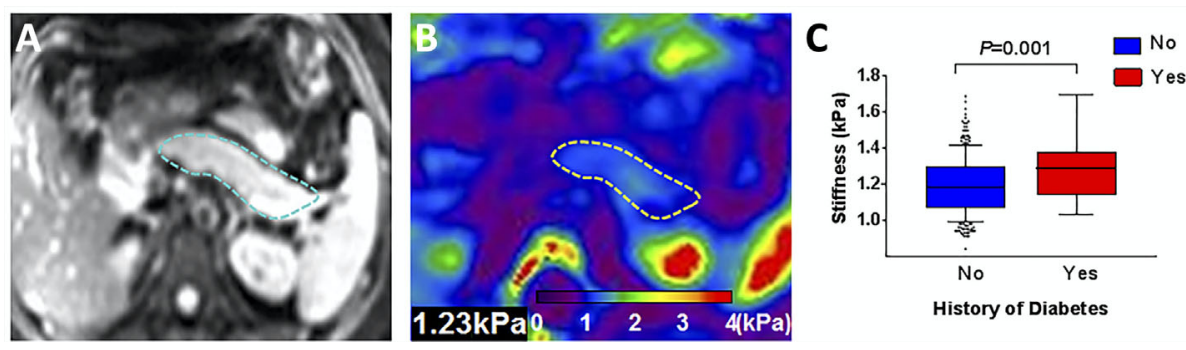

FIGURE 6 | Representative pancreatic axial magnitude images (A, pancreas outlined in blue) and elastograms (B, pancreas outlined in yellow). Box plot in (C) compares pancreas stiffness in individuals with a history of diabetes versus controls. Figure adapted from reference (84) with permission, (C) 2020 John Wiley \& Sons, Inc. 
TABLE 2 | Pancreas magnetic resonance imaging (MRI) analysis techniques.

\begin{tabular}{|c|c|c|}
\hline Technique & Advantages & Disadvantages \\
\hline $\begin{array}{l}\text { Region- } \\
\text { of-interest }\end{array}$ & $\begin{array}{l}\text { Easy to implement; fast; } \\
\text { can avoid ductal structures } \\
\text { and organ borders }\end{array}$ & $\begin{array}{l}\text { Placement affects quantification; } \\
\text { does not capture anatomical } \\
\text { heterogeneity }\end{array}$ \\
\hline $\begin{array}{l}\text { Whole } \\
\text { pancreas } \\
\text { averaging }\end{array}$ & $\begin{array}{l}\text { Not subject to reader } \\
\text { placement; captures all } \\
\text { regions of the pancreas }\end{array}$ & $\begin{array}{l}\text { Averages ductal structures and } \\
\text { organ borders; may average out } \\
\text { sparse alterations; requires capturing } \\
\text { entire pancreas in field of view }\end{array}$ \\
\hline Radiomics & $\begin{array}{l}\text { Quantifies anatomical } \\
\text { heterogeneity; identifies } \\
\text { anatomical regions with } \\
\text { different properties } \\
\text { ("habitats") }\end{array}$ & $\begin{array}{l}\text { Difficult to implement; High } \\
\text { dimensionality of data can result in } \\
\text { overfitting }\end{array}$ \\
\hline
\end{tabular}

Even within the same region of the pancreas, ROI-based calculations may be dependent on the proportion of endocrine, ductal, or fatty infiltrate encompassed in the ROI. A helpful analogy can be found in histology, where analyzing only a single section of a slide induces sampling bias. Averaging measurements over multiple sections and slides gives more robust analysis of histological samples. Similarly, one can average MRI parameters over the entire pancreas, although this technique may be insensitive to sparse alterations, such as those found using DWI in T1D (20). For instance, if only a small portion of the pancreas is affected but the entire pancreas is averaged together, then the preponderance of similar intensity voxels can average out sparse voxels with significantly higher or lower intensities.

The insufficiency of ROI or whole organ-based analyses coupled with advances in high performance computing has led to so-called "radiomic" analysis of medical image data. The field of radiomics, excellently reviewed by Gillies et al. (90), couples high throughput feature extraction from quantitative imaging data with multi-dimensional texture, histogram, shape, and wavelet analysis. These radiomic features are uniquely suited to quantify spatially variant organs, such as the different habitats present in tumors (91). Likewise, radiomic analysis show great promise for characterizing and quantifying the spatial heterogeneity of the diabetic pancreas. For example, we have

\section{REFERENCES}

1. Miller FH, Keppke AL, Dalal K, Ly JN, Kamler VA, Sica GT. MRI of pancreatitis and its complications: part 1, acute pancreatitis. AJR Am J Roentgenol (2004) 183(6):1637-44. doi: 10.2214/ajr.183.6.01831637

2. Miller FH, Keppke AL, Wadhwa A, Ly JN, Dalal K, Kamler VA. MRI of pancreatitis and its complications: part 2, chronic pancreatitis. AJR Am J Roentgenol (2004) 183(6):1645-52. doi: 10.2214/ajr.183.6.01831645

3. Tummala P, Junaidi O, Agarwal B. Imaging of pancreatic cancer: An overview. $J$ Gastrointest Oncol (2011) 2(3):168-74. doi: 10.3978/j.issn.2078-6891.2011.036

4. Cassinotto C, Sa-Cunha A, Trillaud H. Radiological evaluation of response to neoadjuvant treatment in pancreatic cancer. Diagn Interv Imaging (2016) 97 (12):1225-32. doi: 10.1016/j.diii.2016.07.011

5. Alexandre-Heymann L, Mallone R, Boitard C, Scharfmann R, Larger E. Structure and function of the exocrine pancreas in patients with type 1 diabetes. Rev Endocr Metab Disord (2019) 20(2):129-49. doi: 10.1007/s11154019-09501-3 demonstrated that histogram analysis of the pancreas of individuals with T1D identifies differences in DWI that is not evident when averaging the whole pancreas (20). The relative advantages and disadvantages of image analysis techniques for pancreas MRI are summarized in Table 2. Radiomic analysis of the diabetic pancreas has not been well characterized and represents a promising new direction in the field.

\section{CONCLUSION}

Quantitative MRI techniques have been rapidly integrated into clinical practice across a number of medical specialties. Their contribution to endocrinology and the study of the pancreas in diabetes is still under investigation. A number of techniques display promise for improving our understanding of diabetes pathogenesis in the pancreas and evaluating response to therapy. The flexibility of MRI, which gives rise to a plethora of techniques interrogating different aspects of disease, is also a hindrance, in that imaging protocols employ different acquisition and processing techniques. Thus, comparing studies across sites can be difficult. Standardized imaging and processing pipelines are needed in order to compare studies and perform multisite clinical trials. Analysis of quantitative MRI studies of the pancreas will be aided by radiomic analysis in order to account for pancreas heterogeneity, especially the heterogeneity characteristic of the diabetic pancreas.

\section{AUTHOR CONTRIBUTIONS}

The author confirms being the sole contributor of this work and has approved it for publication.

\section{FUNDING}

This work was supported by JDRF International (3-SRA-2019759-M-B and 3-SRA-2015-102-M-B) and the Cain Foundation.

6. Bonora E, Tuomilehto J. The pros and cons of diagnosing diabetes with A1C. Diabetes Care (2011) 34:S184-90. doi: 10.2337/dc11-s216

7. Bonner-Weir S, Trent DF, Weir GC. Partial pancreatectomy in the rat and subsequent defect in glucose-induced insulin release. J Clin Invest (1983) 71 (6):1544-53. doi: 10.1172/JCI110910

8. Jacobsen LM, Bocchino L, Evans-Molina C, DiMeglio L, Goland R, Wilson $\mathrm{DM}$, et al. The risk of progression to type 1 diabetes is highly variable in individuals with multiple autoantibodies following screening. Diabetologia (2020) 63(3):588-96. doi: 10.1007/s00125-019-05047-w

9. Yankeelov TE, Mankoff DA, Schwartz LH, Lieberman FS, Buatti JM, Mountz JM, et al. Quantitative Imaging in Cancer Clinical Trials. Clin Cancer Res (2016) 22(2):284-90. doi: 10.1158/1078-0432.CCR-14-3336

10. Willcox A, Richardson SJ, Bone AJ, Foulis AK, Morgan NG. Analysis of islet inflammation in human type 1 diabetes. Clin Exp Immunol (2009) 155 (2):173-81. doi: 10.1111/j.1365-2249.2008.03860.x

11. Bell ET. Hyalinization of the islets of Langerhans in nondiabetic individuals. Am J Pathol (1959) 35(4):801-5. 
12. Clark A, Wells CA, Buley ID, Cruickshank JK, Vanhegan RI, Matthews DR, et al. Islet amyloid, increased A-cells, reduced B-cells and exocrine fibrosis: quantitative changes in the pancreas in type 2 diabetes. Diabetes Res (1988) 9 (4):151-9.

13. Gepts W. Pathologic anatomy of the pancreas in juvenile diabetes mellitus. Diabetes (1965) 14(10):619-33. doi: 10.2337/diab.14.10.619

14. Saisho Y, Butler AE, Meier JJ, Monchamp T, Allen-Auerbach M, Rizza RA, et al. Pancreas volumes in humans from birth to age one hundred taking into account sex, obesity, and presence of type-2 diabetes. Clin Anat (2007) 20 (8):933-42. doi: 10.1002/ca.20543

15. Garcia TS, Rech TH, Leitao CB. Pancreatic size and fat content in diabetes: A systematic review and meta-analysis of imaging studies. PLoS One (2017) 12 (7):e0180911. doi: 10.1371/journal.pone.0180911

16. Wright JJ, Saunders DC, Dai C, Poffenberger G, Cairns B, Serreze DV, et al. Decreased pancreatic acinar cell number in type 1 diabetes. Diabetologia (2020) 63(7):1418-23. doi: 10.1007/s00125-020-05155-y

17. Kusmartseva I, Beery M, Hiller H, Padilla M, Selman S, Posgai A, et al. Temporal Analysis of Amylase Expression in Control, Autoantibody-Positive, and Type 1 Diabetes Pancreatic Tissues. Diabetes (2020) 69(1):60-6. doi: $10.2337 / \mathrm{db} 19-0554$

18. Gaglia JL, Harisinghani M, Aganj I, Wojtkiewicz GR, Hedgire S, Benoist C, et al. Noninvasive mapping of pancreatic inflammation in recent-onset type-1 diabetes patients. Proc Natl Acad Sci U S A (2015) 112(7):2139-44. doi: 10.1073/pnas.1424993112

19. Williams AJ, Thrower SL, Sequeiros IM, Ward A, Bickerton AS, Triay JM, et al. Pancreatic volume is reduced in adult patients with recently diagnosed type 1 diabetes. J Clin Endocrinol Metab (2012) 97(11):E2109-13. doi: 10.1210/jc.2012-1815

20. Virostko J, Williams J, Hilmes M, Bowman C, Wright JJ, Du L, et al. Pancreas Volume Declines During the First Year After Diagnosis of Type 1 Diabetes and Exhibits Altered Diffusion at Disease Onset. Diabetes Care (2019) 42 (2):248-57. doi: 10.2337/dc18-1507

21. Campbell-Thompson ML, Filipp SL, Grajo JR, Nambam B, Beegle R, Middlebrooks EH, et al. Relative Pancreas Volume Is Reduced in FirstDegree Relatives of Patients With Type 1 Diabetes. Diabetes Care (2019) 42 (2):281-7. doi: $10.2337 / \mathrm{dc} 18-1512$

22. Nanno Y, Wilhelm JJ, Heller D, Schat R, Freeman ML, Trikudanathan G, et al. Combination of pancreas volume and $\mathrm{HbAlc}$ level predicts islet yield in patients undergoing total pancreatectomy and islet autotransplantation. Clin Transplant (2020) 34(8):e14008. doi: 10.1111/ctr.14008

23. Szczepaniak EW, Malliaras K, Nelson MD, Szczepaniak LS. Measurement of pancreatic volume by abdominal MRI: a validation study. PLoS One (2013) 8 (2):e55991. doi: 10.1371/journal.pone.0055991

24. Williams JM, Hilmes MA, Archer B, Dulaney A, Du L, Kang H, et al. Repeatability and Reproducibility of Pancreas Volume Measurements Using MRI. Sci Rep (2020) 10(1):4767. doi: 10.1038/s41598-020-61759-9

25. Williams AJ, Chau W, Callaway MP, Dayan CM. Magnetic resonance imaging: a reliable method for measuring pancreatic volume in Type 1 diabetes. Diabetes Med (2007) 24(1):35-40. doi: 10.1111/j.14645491.2007.02027.x

26. Lee $\mathrm{Y}$, Hirose H, Ohneda M, Johnson JH, McGarry JD, Unger RH. Beta-cell lipotoxicity in the pathogenesis of non-insulin-dependent diabetes mellitus of obese rats: impairment in adipocyte-beta-cell relationships. Proc Natl Acad Sci U S A (1994) 91(23):10878-82. doi: 10.1073/pnas.91.23.10878

27. Heni M, Machann J, Staiger H, Schwenzer NF, Peter A, Schick F, et al. Pancreatic fat is negatively associated with insulin secretion in individuals with impaired fasting glucose and/or impaired glucose tolerance: a nuclear magnetic resonance study. Diabetes Metab Res Rev (2010) 26(3):200-5. doi: 10.1002/dmrr.1073

28. Tushuizen ME, Bunck MC, Pouwels PJ, Bontemps S, van Waesberghe JH, Schindhelm RK, et al. Pancreatic fat content and beta-cell function in men with and without type 2 diabetes. Diabetes Care (2007) 30(11):2916-21. doi: $10.2337 / \mathrm{dc} 07-0326$

29. Kuhn JP, Berthold F, Mayerle J, Volzke H, Reeder SB, Rathmann W, et al. Pancreatic Steatosis Demonstrated at MR Imaging in the General Population: Clinical Relevance. Radiology (2015) 276(1):129-36. doi: 10.1148/ radiol.15140446
30. Patel NS, Peterson MR, Brenner DA, Heba E, Sirlin C, Loomba R. Association between novel MRI-estimated pancreatic fat and liver histology-determined steatosis and fibrosis in non-alcoholic fatty liver disease. Aliment Pharmacol Ther (2013) 37(6):630-9. doi: 10.1111/apt.12237

31. Lim EL, Hollingsworth KG, Aribisala BS, Chen MJ, Mathers JC, Taylor R. Reversal of type 2 diabetes: normalisation of beta cell function in association with decreased pancreas and liver triacylglycerol. Diabetologia (2011) 54 (10):2506-14. doi: 10.1007/s00125-011-2204-7

32. Heber SD, Hetterich H, Lorbeer R, Bayerl C, Machann J, Auweter S, et al. Pancreatic fat content by magnetic resonance imaging in subjects with prediabetes, diabetes, and controls from a general population without cardiovascular disease. PLoS One (2017) 12(5):e0177154. doi: 10.1371/ journal.pone. 0177154

33. Nadarajah C, Fananapazir G, Cui E, Gichoya J, Thayalan N, Asare-Sawiri M, et al. Association of pancreatic fat content with type II diabetes mellitus. Clin Radiol (2020) 75(1):51-6. doi: 10.1016/j.crad.2019.05.027

34. Regnell SE, Peterson P, Trinh L, Broberg P, Leander P, Lernmark A, et al. Pancreas volume and fat fraction in children with Type 1 diabetes. Diabetes Med (2016) 33(10):1374-9. doi: 10.1111/dme.13115

35. Fukui H, Hori M, Fukuda Y, Onishi H, Nakamoto A, Ota T, et al. Evaluation of fatty pancreas by proton density fat fraction using 3-T magnetic resonance imaging and its association with pancreatic cancer. Eur J Radiol (2019) 118:25-31. doi: 10.1016/j.ejrad.2019.06.024

36. Lingvay I, Esser V, Legendre JL, Price AL, Wertz KM, Adams-Huet B, et al. Noninvasive quantification of pancreatic fat in humans. J Clin Endocrinol Metab (2009) 94(10):4070-6. doi: 10.1210/jc.2009-0584

37. Hu HH, Kim HW, Nayak KS, Goran MI. Comparison of fat-water MRI and single-voxel MRS in the assessment of hepatic and pancreatic fat fractions in humans. Obes (Silver Spring) (2010) 18(4):841-7. doi: 10.1038/oby.2009.352

38. Al-Mrabeh A, Hollingsworth KG, Steven S, Tiniakos D, Taylor R. Quantification of intrapancreatic fat in type 2 diabetes by MRI. PLoS One (2017) 12(4):e0174660. doi: 10.1371/journal.pone.0174660

39. Manikkavasakar S, AlObaidy M, Busireddy KK, Ramalho M, Nilmini V, Alagiyawanna $M$, et al. Magnetic resonance imaging of pancreatitis: an update. World J Gastroenterol (2014) 20(40):14760-77. doi: 10.3748/ wjg.v20.i40.14760

40. Taylor AJ, Salerno M, Dharmakumar R, Jerosch-Herold M. T1 Mapping: Basic Techniques and Clinical Applications. JACC Cardiovasc Imaging (2016) 9(1):67-81. doi: 10.1016/j.jcmg.2015.11.005

41. Tirkes T, Lin C, Fogel EL, Sherman SS, Wang Q, Sandrasegaran K. T1 mapping for diagnosis of mild chronic pancreatitis. J Magn Reson Imaging (2017) 45(4):1171-6. doi: 10.1002/jmri.25428

42. Noda Y, Goshima S, Tsuji Y, Kajita K, Akamine Y, Kawai N, et al. Pancreatic extracellular volume fraction using T1 mapping in patients with impaired glucose intolerance. Abdom Radiol (NY) (2020) 45(2):449-56. doi: 10.1007/ s00261-019-02384-7

43. Naish JH, Hutchinson CE, Caunce A, Roberts C, Waterton JC, Hockings PD, et al. Multiple-bolus dynamic contrast-enhanced MRI in the pancreas during a glucose challenge. J Magn Reson Imaging (2010) 32(3):622-8. doi: 10.1002/jmri.22281

44. Noda Y, Goshima S, Tsuji Y, Kajita K, Kawada H, Kawai N, et al. Correlation of quantitative pancreatic $\mathrm{T} 1$ value and $\mathrm{HbAlc}$ value in subjects with normal and impaired glucose tolerance. J Magn Reson Imaging (2019) 49(3):711-8. doi: $10.1002 /$ jmri.26242

45. Sibley CT, Noureldin RA, Gai N, Nacif MS, Liu S, Turkbey EB, et al. T1 Mapping in cardiomyopathy at cardiac MR: comparison with endomyocardial biopsy. Radiology (2012) 265(3):724-32. doi: 10.1148/radiol.12112721

46. Watanabe H, Kanematsu M, Tanaka K, Osada S, Tomita H, Hara A, et al. Fibrosis and postoperative fistula of the pancreas: correlation with MR imaging findings-preliminary results. Radiology (2014) 270(3):791-9. doi: 10.1148/radiol.13131194

47. Tirkes T, Mitchell JR, Li L, Zhao X, Lin C. Normal T1 relaxometry and extracellular volume of the pancreas in subjects with no pancreas disease: correlation with age and gender. Abdom Radiol (NY) (2019) 44(9):3133-8. doi: 10.1007/s00261-019-02071-7

48. Damen M, van Leeuwen M, Webb A, Klomp D, de Castro CA. Measurement of $\mathrm{T} 1$ and $\mathrm{T} 2$ relaxation times of the pancreas at $7 \mathrm{~T}$ using a multi-transmit system. MAGMA (2019) 32(6):703-8. doi: 10.1007/s10334-019-00768-w 
49. Tirkes T, Zhao X, Lin C, Stuckey AJ, Li L, Giri S, et al. Evaluation of variable flip angle, MOLLI, SASHA, and IR-SNAPSHOT pulse sequences for T1 relaxometry and extracellular volume imaging of the pancreas and liver. MAGMA (2019) 32(5):559-66. doi: 10.1007/s10334-019-00762-2

50. Haaf P, Garg P, Messroghli DR, Broadbent DA, Greenwood JP, Plein S. Cardiac T1 Mapping and Extracellular Volume (ECV) in clinical practice: a comprehensive review. J Cardiovasc Magn Reson (2016) 18(1):89. doi: 10.1186/s12968-016-0308-4

51. Tirkes T, Lin C, Cui E, Deng Y, Territo PR, Sandrasegaran K, et al. Quantitative MR Evaluation of Chronic Pancreatitis: Extracellular Volume Fraction and MR Relaxometry. AJR Am J Roentgenol (2018) 210(3):533-42. doi: 10.2214/AJR.17.18606

52. Cui Y, Cao Y, Song J, Dong N, Kong X, Wang J, et al. Association between myocardial extracellular volume and strain analysis through cardiovascular magnetic resonance with histological myocardial fibrosis in patients awaiting heart transplantation. J Cardiovasc Magn Reson (2018) 20(1):25. doi: 10.1186/ s12968-018-0445-z

53. Roujol S, Weingartner S, Foppa M, Chow K, Kawaji K, Ngo LH, et al. Accuracy, precision, and reproducibility of four T1 mapping sequences: a head-to-head comparison of MOLLI, ShMOLLI, SASHA, and SAPPHIRE. Radiology (2014) 272(3):683-9. doi: 10.1148/radiol.14140296

54. Lee SS, Byun JH, Park BJ, Park SH, Kim N, Park B, et al. Quantitative analysis of diffusion-weighted magnetic resonance imaging of the pancreas: usefulness in characterizing solid pancreatic masses. J Magn Reson Imaging (2008) 28 (4):928-36. doi: 10.1002/jmri.21508

55. Akisik MF, Aisen AM, Sandrasegaran K, Jennings SG, Lin C, Sherman S, et al. Assessment of chronic pancreatitis: utility of diffusion-weighted MR imaging with secretin enhancement. Radiology (2009) 250(1):103-9. doi: 10.1148/ radiol.2493080160

56. Noda Y, Kanematsu M, Goshima S, Horikawa Y, Takeda J, Kondo H, et al. Diffusion kurtosis imaging of the pancreas for the assessment of $\mathrm{HbAlc} \mathrm{levels.}$ J Magn Reson Imaging (2016) 43(1):159-65. doi: 10.1002/jmri.24982

57. Schoennagel BP, Habermann CR, Roesch M, Hahne JD, Arndt C, Kleibeler L, et al. Diffusion-weighted imaging of the healthy pancreas: apparent diffusion coefficient values of the normal head, body, and tail calculated from different sets of b-values. J Magn Reson Imaging (2011) 34(4):861-5. doi: 10.1002/ jmri.22743

58. Herrmann J, Schoennagel BP, Roesch M, Busch JD, Derlin T, Doh LK, et al. Diffusion-weighted imaging of the healthy pancreas: ADC values are age and gender dependent. J Magn Reson Imaging (2013) 37(4):886-91. doi: 10.1002/ jmri.23871

59. Ye XH, Gao JY, Yang ZH, Liu Y. Apparent diffusion coefficient reproducibility of the pancreas measured at different MR scanners using diffusion-weighted imaging. J Magn Reson Imaging (2014) 40(6):1375-81. doi: 10.1002/ jmri.24492

60. Dale BM, Braithwaite AC, Boll DT, Merkle EM. Field strength and diffusion encoding technique affect the apparent diffusion coefficient measurements in diffusion-weighted imaging of the abdomen. Invest Radiol (2010) 45(2):104-8. doi: 10.1097/RLI.0b013e3181c8ceac

61. Henderson JR, Moss MC. A morphometric study of the endocrine and exocrine capillaries of the pancreas. Q J Exp Physiol (1985) 70(3):347-56. doi: 10.1113/expphysiol.1985.sp002920

62. Canzano JS, Nasif LH, Butterworth EA, Fu DA, Atkinson MA, CampbellThompson M. Islet Microvasculature Alterations With Loss of Beta-cells in Patients With Type 1 Diabetes. J Histochem Cytochem (2019) 67(1):41-52. doi: $10.1369 / 0022155418778546$

63. Brissova M, Shostak A, Fligner CL, Revetta FL, Washington MK, Powers AC, et al. Human Islets Have Fewer Blood Vessels than Mouse Islets and the Density of Islet Vascular Structures Is Increased in Type 2 Diabetes. J Histochem Cytochem (2015) 63(8):637-45. doi: 10.1369/0022155415573324

64. Tofts PS, Kermode AG. Measurement of the blood-brain barrier permeability and leakage space using dynamic MR imaging. 1. Fundamental concepts. Magn Reson Med (1991) 17(2):357-67. doi: 10.1002/mrm.1910170208

65. Coenegrachts K, Van Steenbergen W, De Keyzer F, Vanbeckevoort D, Bielen D, Chen F, et al. Dynamic contrast-enhanced MRI of the pancreas: initial results in healthy volunteers and patients with chronic pancreatitis. J Magn Reson Imaging (2004) 20(6):990-7. doi: 10.1002/jmri.20212
66. Akisik MF, Sandrasegaran K, Bu G, Lin C, Hutchins GD, Chiorean EG. Pancreatic cancer: utility of dynamic contrast-enhanced MR imaging in assessment of antiangiogenic therapy. Radiology (2010) 256(2):441-9. doi: 10.1148/radiol.10091733

67. Yu CW, Shih TT, Hsu CY, Lin LC, Wei SY, Lee CM, et al. Correlation between pancreatic microcirculation and type 2 diabetes in patients with coronary artery disease: dynamic contrast-enhanced MR imaging. Radiology (2009) 252 (3):704-11. doi: 10.1148/radiol.2523081615

68. Bali MA, Metens T, Denolin V, Delhaye M, Demetter P, Closset J, et al. Tumoral and nontumoral pancreas: correlation between quantitative dynamic contrast-enhanced MR imaging and histopathologic parameters. Radiology (2011) 261(2):456-66. doi: 10.1148/radiol.11103515

69. Bali MA, Metens T, Denolin V, De Maertelaer V, Deviere J, Matos C. Pancreatic perfusion: noninvasive quantitative assessment with dynamic contrast-enhanced MR imaging without and with secretin stimulation in healthy volunteers-initial results. Radiology (2008) 247(1):115-21. doi: 10.1148/radiol.2471070685

70. Schawkat K, Ith M, Christe A, Kuhn W, Chittazhathu Y, Bains L, et al. Dynamic non-invasive ASL perfusion imaging of a normal pancreas with secretin augmented MR imaging. Eur Radiol (2018) 28(6):2389-96. doi: 10.1007/s00330-017-5227-8

71. Taso M, Papadopoulou F, Smith MP, Tsai LL, Mortele KJ, Alsop DC. Pancreatic perfusion modulation following glucose stimulation assessed by noninvasive arterial spin labeling (ASL) MRI. J Magn Reson Imaging (2020) 51 (3):854-60. doi: 10.1002/jmri.26899

72. Hirshberg B, Qiu M, Cali AM, Sherwin R, Constable T, Calle RA, et al. Pancreatic perfusion of healthy individuals and type 1 diabetic patients as assessed by magnetic resonance perfusion imaging. Diabetologia (2009) 52 (8):1561-5. doi: 10.1007/s00125-009-1406-8

73. Cai W, Li F, Wang J, Du H, Wang X, Zhang J, et al. A comparison of arterial spin labeling perfusion MRI and DCE-MRI in human prostate cancer. NMR Biomed (2014) 27(7):817-25. doi: 10.1002/nbm.3124

74. Schraml C, Schwenzer NF, Martirosian P, Claussen CD, Schick F. Perfusion imaging of the pancreas using an arterial spin labeling technique. J Magn Reson Imaging (2008) 28(6):1459-65. doi: 10.1002/jmri.21564

75. Le Bihan D, Breton E, Lallemand D, Aubin ML, Vignaud J, Laval-Jeantet M. Separation of diffusion and perfusion in intravoxel incoherent motion MR imaging. Radiology (1988) 168(2):497-505. doi: 10.1148/radiology.168.2.3393671

76. Kim B, Lee SS, Sung YS, Cheong H, Byun JH, Kim HJ, et al. Intravoxel incoherent motion diffusion-weighted imaging of the pancreas: Characterization of benign and malignant pancreatic pathologies. J Magn Reson Imaging (2017) 45(1):260-9. doi: 10.1002/jmri.25334

77. Espes D, Manell E, Ryden A, Carlbom L, Weis J, Jensen-Waern M, et al. Pancreatic perfusion and its response to glucose as measured by simultaneous PET/MRI. Acta Diabetol (2019) 56(10):1113-20. doi: 10.1007/s00592-01901353-2

78. Lemke A, Laun FB, Simon D, Stieltjes B, Schad LR. An in vivo verification of the intravoxel incoherent motion effect in diffusion-weighted imaging of the abdomen. Magn Reson Med (2010) 64(6):1580-5. doi: 10.1002/mrm.22565

79. Gurney-Champion OJ, Klaassen R, Froeling M, Barbieri S, Stoker J, Engelbrecht MRW, et al. Comparison of six fit algorithms for the intravoxel incoherent motion model of diffusion-weighted magnetic resonance imaging data of pancreatic cancer patients. PLoS One (2018) 13(4):e0194590. doi: 10.1371/journal.pone. 0194590

80. Prasad PV, Edelman RR, Epstein FH. Noninvasive evaluation of intrarenal oxygenation with BOLD MRI. Circulation (1996) 94(12):3271-5. doi: 10.1161/01.CIR.94.12.3271

81. Chen B, Chen W, Chan Q, Zhou N, He J, Zhou Z. Functional MRI of human pancreas using BOLD contrast: Responses following glucose ingestion. J Magn Reson Imaging (2017) 46(3):831-6. doi: 10.1002/jmri.25640

82. Serai SD, Abu-El-Haija M, Trout AT. 3D MR elastography of the pancreas in children. Abdom Radiol (NY) (2019) 44(5):1834-40. doi: 10.1007/s00261-01901903-w

83. Ji R, Li J, Yin Z, Liu Y, Cang L, Wang M, et al. Pancreatic stiffness response to an oral glucose load in obese adults measured by magnetic resonance elastography. Magn Reson Imaging (2018) 51:113-9. doi: 10.1016/ j.mri.2018.04.019 
84. Xu Y, Cai X, Shi Y, Yin M, Lan G, Zhang X, et al. Normative Pancreatic Stiffness Levels and Related Influences Established by Magnetic Resonance Elastography in Volunteers. J Magn Reson Imaging (2020) 52(2):448-58. doi: 10.1002/jmri.27052

85. Shi Y, Liu Y, Gao F, Liu Y, Tao S, Li Y, et al. Pancreatic Stiffness Quantified with MR Elastography: Relationship to Postoperative Pancreatic Fistula after Pancreaticoenteric Anastomosis. Radiology (2018) 288(2):476-84. doi: 10.1148/radiol.2018170450

86. Kolipaka A, Schroeder S, Mo X, Shah Z, Hart PA, Conwell DL. Magnetic resonance elastography of the pancreas: Measurement reproducibility and relationship with age. Magn Reson Imaging (2017) 42:1-7. doi: 10.1016/ j.mri.2017.04.015

87. Wittingen J, Frey CF. Islet concentration in the head, body, tail and uncinate process of the pancreas. Ann Surg (1974) 179(4):412-4. doi: 10.1097/ 00000658-197404000-00005

88. Cecil RL. A Study of the Pathological Anatomy of the Pancreas in Ninety Cases of Diabetes Mellitus. J Exp Med (1909) 11(2):266-90. doi: 10.1084/ jem.11.2.266

89. Rodriguez-Calvo T, Suwandi JS, Amirian N, Zapardiel-Gonzalo J, Anquetil F, Sabouri S, et al. Heterogeneity and Lobularity of Pancreatic Pathology in Type
1 Diabetes during the Prediabetic Phase. J Histochem Cytochem (2015) 63 (8):626-36. doi: 10.1369/0022155415576543

90. Gillies RJ, Kinahan PE, Hricak H. Radiomics: Images Are More than Pictures, They Are Data. Radiology (2016) 278(2):563-77. doi: 10.1148/ radiol.2015151169

91. Zhou M, Hall L, Goldgof D, Russo R, Balagurunathan Y, Gillies R, et al. Radiologically defined ecological dynamics and clinical outcomes in glioblastoma multiforme: preliminary results. Transl Oncol (2014) 7(1):513. doi: $10.1593 /$ tlo. 13730

Conflict of Interest: The author declares that the research was conducted in the absence of any commercial or financial relationships that could be construed as a potential conflict of interest.

Copyright (c) 2020 Virostko. This is an open-access article distributed under the terms of the Creative Commons Attribution License (CC BY). The use, distribution or reproduction in other forums is permitted, provided the original author(s) and the copyright owner(s) are credited and that the original publication in this journal is cited, in accordance with accepted academic practice. No use, distribution or reproduction is permitted which does not comply with these terms. 